\title{
Passado imprevisível num tempo imprevisível: O centenário da Revolução de 1917 na Rússia contemporânea*
}

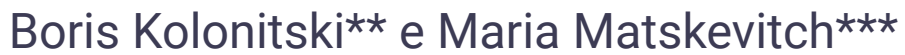

Resumo: Na Rússia, a política da memória adquire um papel de destaque em decorrência da limitação da política pública. Nas altas esferas oficiais, o centenário da revolução de 1917 é praticamente ignorado, embora sejam permitidas discussões científicas e a realização de projetos expositivos e educativos. Os atores políticos quase não usam a memória da revolução, e no espaço público estão ausentes eventos relevantes ligados ao centenário. A história da revolução é considerada "passado não-utilizável". A memória cultural influencia a política da memória. A avaliação sobre as consequências da revolução por parte dos cidadãos russos é contraditória e pouco mudou desde 1990. Junto com isso, a maioria nega a possibilidade de uma nova revolução. A tendência dos últimos anos é o distanciamento no nível de conhecimento histórico e percepção do passado entre a geração mais velha e a mais nova.

\begin{abstract}
In Russia, the politics of memory play a special role, in view of the limits on public politics. At the highest official level, the anniversary of the Revolutions of 1917 is being ignored, although academic discussions are permitted. There are also exhibits and educational projects. Political figures do not refer to the memory of the revolution, and there are no significant events in the public space linked to the anniversary. The history of the revolution is «unusable past.» Cultural memory influences the politics of memory. Citizens' assessment of the consequences of the revolution is contradictory and has changed little since 1990, and the majority deny any possibility of a new revolution. The tendency of the last years is that of a divide in historical knowledge and assement of the past between the older and younger generations.
\end{abstract}

Palavras-chave: Revolução Russa de 1917, centenário, política da memória, memória cultural.

Ключевые слова: Русская революция 1917 года, юбилей, политика памяти, культурная память. 
*Artigo submetido em 08 de novembro de 2017 e aprovado em 11 de dezembro de 2017. **Doutor em história, professor da Universidade Europeia de São Petersburgo, pesquisador-líder do Instituto de História de São Petersburgo da Academia Russa de Ciências. E-mail: boris_i_kol@mail.ru ***Doutora em sociologia, pesquisadora-sênior do Instituto Sociológico da Academia Russa de Ciências. E-mail:mmatskevich@ yandex.ru

\section{II C omo serão as comemorações do centenário} da revolução na Rússia?" Já faz alguns anos que escutamos essa pergunta de nossos colegas estrangeiros. Entretanto, mesmo agora, em setembro de 2017, não podemos dar uma resposta precisa: não sabemos o que correrá em novembro. A Rússia é frequentemente descrita como "um país com um passado imprevisível": os regimes que se sucediam reescreviam apaixonadamente a história a partir de seus próprios objetivos políticos. Agora, nosso país pode ser descrito como um país com um passado especialmente imprevisível: seu desenvolvimento político no próximo período é imprevisível, qualquer mudança pode se expressar também na política da memória, ${ }^{1}$ que assume um papel especialmente importante em condições de limitação da política pública.

Ao descrever a política da memória na Rússia contemporânea, os analistas prestam especial atenção às declarações do presidente da Federação Russa Vladimir Putin. Exatamente nelas busca-se a chave para a compreensão da política da memória promovida pelo Estado. Em dezembro de 2016, ao dirigir-se à Assembleia Federal, ${ }^{2}$ o presidente Putin chamou a que se usasse o recurso do aniversário da revolução "para a pacificação, para o fortalecimento do consenso social, político e civil". Ao mesmo tempo, Putin colocou-se contra o que considerou um uso abusivo do passado: "É inadmissível promover a ruptura, o ódio, a ofensa e o acirramento do passado em nossa vida atual; especular, em nome de interesses políticos próprios e de outros tipos, com a tragédia que atingiu praticamen-

\footnotetext{
1 Política da memória: conceito surgido nos últimos anos nos estudos culturais russos. Designa as ações do Estado russo que têm por objetivo influenciar a memória histórica coletiva e a interpretação do passado russo. A política da memória (também referida por alguns autores como "guerra da memória") tem desdobramentos na política cultural, científica, de comunicação etc. (N. do T.)

2 Parlamento russo em seu conjunto, formado pelas câmaras baixa e alta: a Duma de Estado e o Conselho da Federação. (N. do T.)
} 


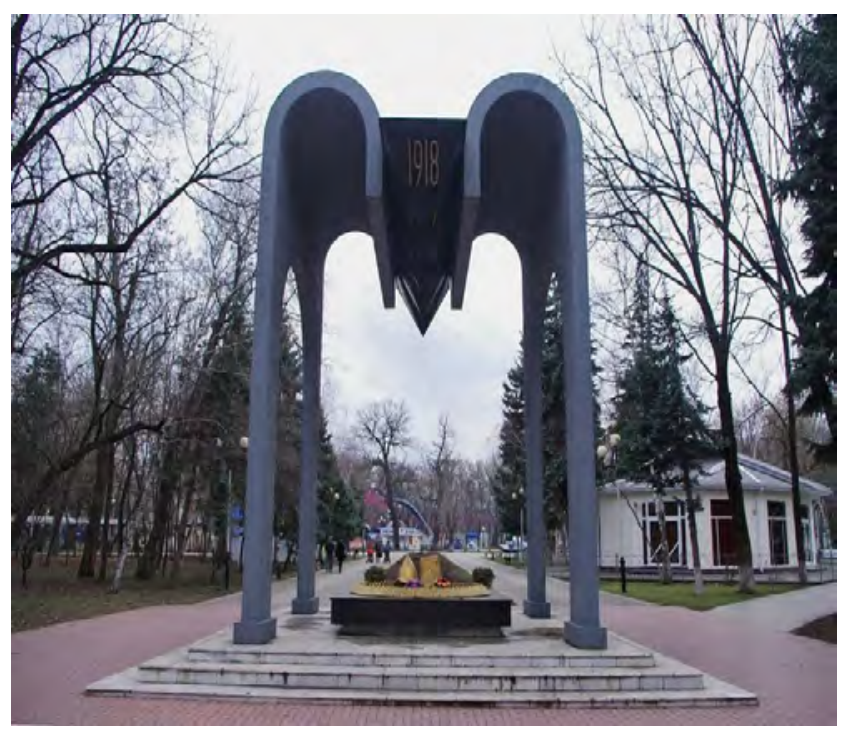

te todas as famílias da Rússia, independente do lado das barricadas no qual se encontravam nossos ancestrais". ${ }^{3}$ Não se pode dizer que esse projeto de pacificação e consenso é imposto apenas pelo centro federal. Existe com relação a ele uma certa demanda social. É ilustrativo, por exemplo, que monumentos à pacificação nacional já tenham sido erigidos em Novotcherkassk e Krasnodar.

No dia 19 de dezembro, Putin assinou uma ordem executiva para a preparação e realização de eventos relacionados ao centenário da revolução de 1917. Em função desta ordem, a Sociedade Histórica Russa formou um Comitê

Monumento à pacificação e ao consenso em Krasnodar (inaugurado em 1998). Fonte: http:// krasnodar861.ru/ gorod/345-pamyatnikprimireniya-i-soglasiya. html
Organizativo para a realização de atividades comemorativas e o Ministério da Cultura forneceu os fundos para sua concretização. Entre as atividades aprovadas pelo Comitê Organizativo, pode-se citar projetos expositivos, educativos, editoriais e científicos. ${ }^{4}$ Alguns desses projetos já foram concretizados e se realizaram conferências de diferentes dimensões. Não se pode dizer, contudo, que qualquer uma das atividades dessa lista tenha provocado uma grande discussão social. A lista das atividades especificamente comemorativas e cerimônias oficiais é incrivelmente curta. É verdade que nesta lista figura a inauguração, em 4 de novembro, do monumento à pacificação na Crimeia, em Sebastopol. Esse poderia ser um evento de importância. Entretanto, aparentemente, ninguém sabe se esse monumento será erguido. Em todo caso, a campanha para a arrecadação de fundos com vistas à construção desse monumento não pode ser considerada bem sucedida. Além disso, tal iniciativa provocou protestos. Não houve consenso.

As palavras de Putin foram tomadas por muitos na Rússia como uma orientação para a ação. Entretanto, não seria correto, em nossa opinião, exagerar seus significado. E não seria

\footnotetext{
${ }^{3}$ Fonte: Portal oficial do presidente da Rússia: http://www.kremlin.ru/events/president/ news/53379

${ }^{4} O$ plano das atividades promovidas pelo Estado foi publicado no portal da Sociedade Histórica Russa: http://rushistory.org/images/documents/plan100letrevolution.pdf
} 
B. Kolonitski e M. Matskevitch

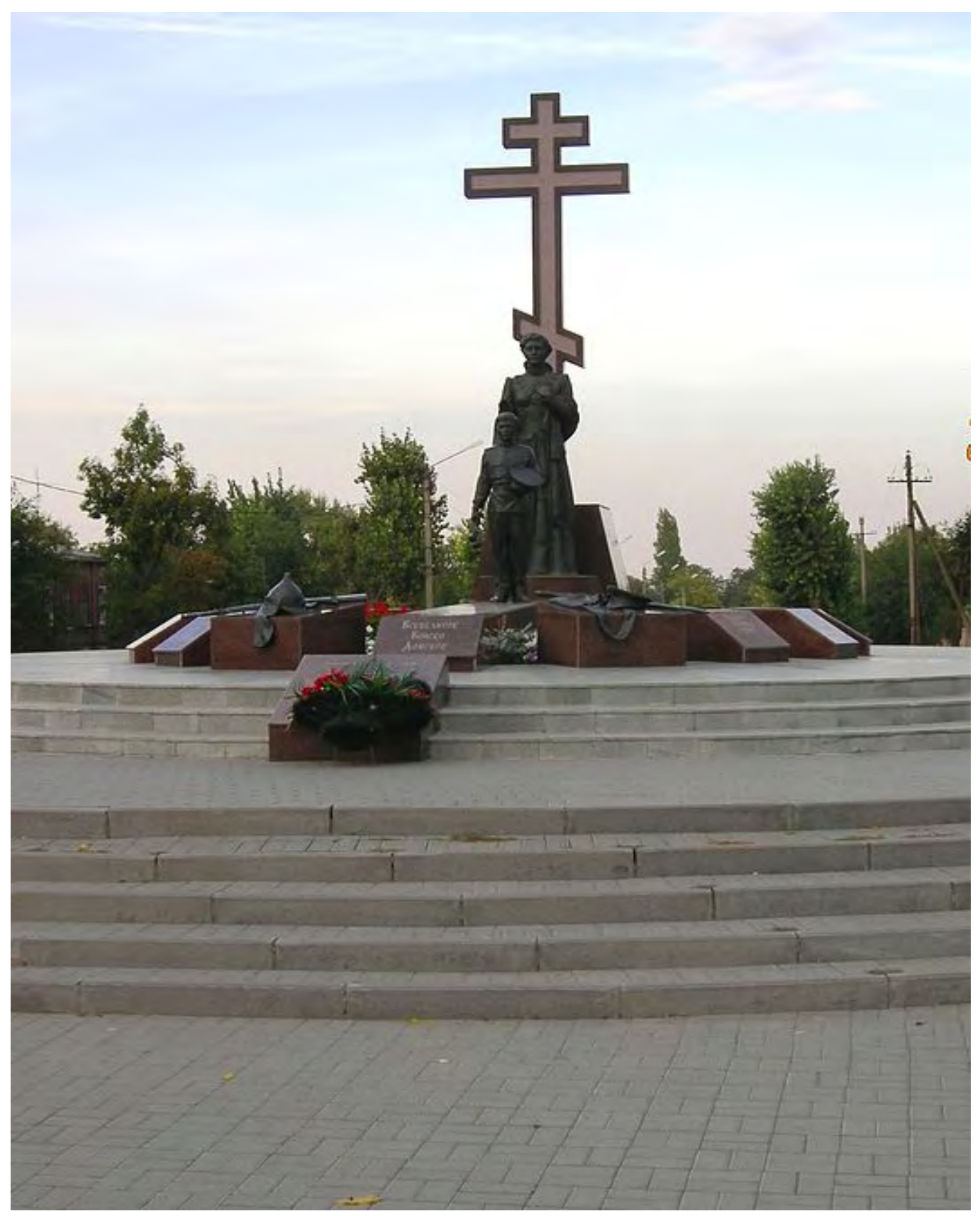

Monumento à pacificação e ao consenso em Novotcherkassk (inaugurado em 2005) Fonte: https:// ru.wikipedia.org/wiki/Памятник_Примирения_и_ Согласия_(Новочеркасск) 
correto interpretar o aniversário ou descrevê-lo simplesmente como sendo o cumprimento das ordens do presidente.

Em primeiro lugar, o próprio Putin está limitado por suas declarações e ações anteriores. Obviamente, na história, há muitos casos em que os políticos mudam radicalmente sua orientação. Entretanto, tais giros abruptos estão ligados a riscos evidentes, que, em geral, os políticos buscam evitar. Assim, em 2014, comemorou-se amplamente na Rússia o início da Primeira Guerra Mundial. Em seu discurso durante a inauguração do monumento aos heróis daquela guerra, o presidente da Federação Russa declarou que a vitória foi roubada da Rússia pelas forças que realizaram um golpe. ${ }^{5}$ Neste discurso, ele não definiu com precisão esses "inimigos internos", mas em algumas de suas declarações caracterizou negativamente Lenin. ${ }^{6}$

Em segundo lugar, o aniversário representa um recurso que é difícil - até mesmo impossível - de ser monopolizado. Assim, por exemplo, no período soviético, as datas comemorativas eram utilizadas para a promoção dos mais variados projetos, às vezes contraditórios uns com os outros. Isso se manifestou de maneira muito clara no período da "perestroika", quando as palavras de ordem de Outubro eram às vezes utilizadas na luta contra o monopólio do poder por parte do Partido Comunista. A palavra de ordem de "Todo o poder aos sovietes!" recebeu, nesta situação, uma nova vida.

Em terceiro lugar, qualquer projeto de memória é um recurso limitado. Não estamos falando apenas sobre os recursos materiais e humanos capazes de realizar tal projeto, mas também sobre as especificidades da memória cultural, sobre os conhecimentos históricos daqueles aos quais as mensagens correspondentes são endereçadas, porque a sua percepção é definida por tais fatores. As mensagens devem ser entendidas e interpretadas da forma apropriada.

${ }^{5}$ Fonte: Portal oficial do Presidente da Rússia: http://www.kremlin.ru/events/president/ news/46385.

${ }^{6}$ A respeito da memória russa sobre a Primeira Guerra Mundial, ver: KOLONITSKI, 2017, p. $179-202$. 
Quais são os limitadores dessa política?

Há várias datas às quais podem ser associadas distintas ações comemorativas: em março de 1917 (fevereiro pelo calendário antigo) a monarquia foi derrubada na Rússia, e em novembro do mesmo ano (outubro pelo calendário antigo) os bolcheviques chegaram ao poder. Enquanto as estruturas de poder silenciavam sobre o aniversário da revolução, o centenário da queda da monarquia em fevereiro e março não foi marcado por ações significativas. Foram organizadas exposições, realizaram-se conferências científicas, surgiram novos livros (embora tenham saído até agora claramente menos livros em comparação com 2014, quando as livrarias estavam cheias de edições dedicadas à Primeira Guerra Mundial). Os meios de comunicação cobriram os eventos de 100 anos atrás (alguns projetos foram financiados com dinheiro público), mas até agora não houve nenhuma cerimônia oficial ligada ao aniversário. As estruturas de poder, ao que parece, tentam ignorar o aniversário, relacionando a história da revolução com o passado "não-utilizável", inútil para as tarefas políticas atuais.

Às vezes, esse silêncio sobre o aniversário é explicado pelo medo diante da "exportação da revolução", sentido pela elite política russa atual. Isso é indicado por observadores e analistas tanto estrangeiros, ${ }^{7}$ quanto russos. ${ }^{8}$ Tornaram-se quase que lugares-comuns expressões como: "O presidente Putin odeia a própria ideia de revolução", "A narrativa do Kremlin de que... o Ocidente luta por implantar em toda parte governos que lhe sejam amigáveis através da promoção das 'revoluções coloridas"'.9

De fato, alguns meios de comunicação e mesmo historiadores isolados chamam a derrubada da monarquia de "revolução colorida", dando demasiada atenção à intervenção externa nos assuntos domésticos da Rússia e a todo tipo de conspiração. ${ }^{10}$

\footnotetext{
${ }^{7}$ Cf. Schmemann, 2017; Pomeranz, 2017; BASTIÉ, 2017.

${ }^{8}$ Cf. Шелин, 2017; Яковлева, 2017; Калинин, 2017, с.11-20.

${ }^{9}$ Mac Farquhar, 2017.

${ }^{10} \mathrm{Cf}$. Пономарева, 2017, sobre porque os golpes políticos da atualidade repetem o esquema da Revolução de Fevereiro de 1917: "O Fundo Andrei Pervozvanni deu início ao projeto
} 
Também o presidente Putin, como já vimos, em algumas de suas declarações anteriores, falou sobre o golpe pelas costas dado contra o heroico exército russo durante a Primeira Guerra Mundial. ${ }^{11}$ Esta versão se expressa em algumas tendências de desenvolvimento da opinião pública. Assim, segundo dados do Centro Levada, em 1990, 6\% dos entrevistados consideravam que a causa da revolução tinha sido "a conspiração dos inimigos do povo russo". Em 1997 este número subiu para 11\%. Depois de 2014, a busca por inimigos no passado e no presente se tornou ainda mais popular, tanto entre a elite, quanto entre o público em geral, e o número de partidários da interpretação conspirológica da história chegou a 20\% em 2017. ${ }^{12}$

Entretanto, a crença em conspirações, mesmo quando sincera, não pode por si só explicar a não-utilização do recurso do aniversário. Além disso, em 2017 percebe-se uma certa redução do número de meios de comunicação que se dedicam às conspirações de há 100 anos atrás, ainda que este tema continue surgindo.

É pouco provável que a direção política do país tema uma explosão revolucionária: se acreditarmos nas pesquisas de opinião, a maioria dos habitantes do país acredita que a Rússia atual deve evitar a qualquer custo uma nova revolução. Ainda em 2012 (no início daquele ano ocorreram as maiores manifestações de protesto na Rússia dos anos 2000), 78\% dos entrevistados pelo Centro Pan-Russo de Estudos de Opinião

educativo 'Rússia 1917. Imagens do futuro'. A tarefa do projeto é contribuir com a obtenção de um amplo consenso social relativo à inadmissibilidade da repetição dos eventos que conduziram àquela enorme crise civilizacional". Fonte: http://rushistory.org/sobytiya/ rekonstruktsiya-vyborov-v-uchreditelnoe-sobranie-1917-goda.html; Цветные революции как последнее средство политики Запада (http://inance.ru/2016/03/revolutsii/) e muitos outros.

11 "...a vitória [na Primeira Guerra Mundial] foi roubada do país. Roubada por aqueles que pregavam a derrota de sua pátria, do seu exército, que disseminavam a divisão dentro da Rússia, que buscavam o poder, traindo os interesses nacionais". Fonte: Portal oficial do Presidente da Rússia (http://www.kremlin.ru/events/president/news/46385); "Nosso país perdeu essa guerra para o lado perdedor. Uma situação única na história da humanidade!... E isso foi o resultado da traição nacional da então liderança do país". Fonte: http://www. kremlin.ru/events/president/transcripts/deliberations/15781

${ }^{12}$ Fonte: Centro Levada - pesquisa por amostragem entre a população adulta, março de 2017: https://www.levada.ru/2017/04/05/oktyabrskaya-revolyutsiya-2/ 
Pública escolheram a variante de resposta "que não aconteça, não se pode permitir uma revolução no país". ${ }^{13}$ Esta opinião é compartilhada por intelectuais populares,$^{14}$ agentes da cultu$\mathrm{ra}_{1}{ }^{15}$ líderes oposicionistas ${ }^{16} \mathrm{e}$ até por alguns participantes das ações de protesto: estes últimos supõem que, com suas ações, ajudam a evitar uma nova revolução. ${ }^{17}$

Este consenso antirrevolucionário, que é um elemento da cultura política da Rússia atual, serve de importante recurso ao poder. Segundo dados de pesquisas nacionais, ocorreu uma mudança na conotação do conceito de "revolução" na consciência da massa: de positiva (dominante não apenas no período soviético, mas também durante a perestroika) para negativa. Além disso, a mudança na conotação ocorreu fundamentalmente nos anos 1990 e foi associada não tanto com a revolução de 1917, quanto com a avaliação (mais frequente-

\footnotetext{
${ }^{13}$ Fonte: pesquisa por amostragem feita pelo CРEОР (ВЦИОМ), outubro de 2012: (https:// wciom.ru/index.php?id=236\&uid=113319)

${ }^{14}$ Por exemplo, o cientista político Vladimir Pastukhov escreve: "Eu não conclamo a uma nova revolução nem justifico uma revolução... Pessoalmente, eu preferiria que a Rússia não precisasse de uma" (https://www.novayagazeta.ru/articles/2012/08/13/50971-gosudarstvo-diktatury-lyumpen-proletariata); o escritor Dmitri Bikov diz: "revolução, quando as massas chegam e dizem 'ei, vocês, desçam' - isso [a Rússia] não viu e queira Deus que não veja". Fonte: entrevista à rádio "Eco de Moscou", 24.10 .2014 (http://echo.msk.ru/programs/ personalno/1424030-echo/); o economista Mikhail Deliaguin diz: "a revolução... desencadeia o mecanismo do caos, que depois pode não ser contido", 17.04.2007. Fonte: http://www. kasparov. .ru/material. .php?id=4624C31AD100A .

${ }^{15}$ Por exemplo, o diretor de teatro Mark Rozovski diz em uma entrevista: "Eu tenho medo de uma revolução, mas não se pode viver na escravidão": https://www.svoboda. org/a/28420794.html; a popular atriz e dirigente do fundo de caridade "Presenteie Vida", Tchulpan Khamatova, assim respondeu à pergunta sobre o que ela prefere - viver num país como a Coreia do Norte... ou uma revolução?: "eu escolheria a Coreia do Norte". Fonte: entrevista ao canal de televisão "Dojd", 7.06 .2012 (https://tvrain.ru/teleshow/ sobchak_zhivem/chulpan_khamatova_ya_by_vybrala_severnuyu_koreyu_a_ne_revolyutsiyu-286479/?utm_source=twi\&utm_medium=social\&utm_campaign=teleshow-sobchak_zhivem\&utm_term=286479); em seu espetáculo, a diretora Ekaterina Koroliova muda o final do conto infantil "Cipollino", escrito pelo comunista italiano Gianni Rodari. A revolta não ocorre, as mudanças vêm "de cima", todos fazem as pazes: "já que eu morro de medo de qualquer revolução, então a mudança ocorre na cabeça dos heróis". Fonte: RIA Novosti, 13.11.2013 (https://ria.ru/culture/20131113/976587606.html).
}

\footnotetext{
${ }^{16}$ Por exemplo, o líder do partido oposicionista labloko, Grigori lavlinski, diz: "revolução é uma coisa muito perigosa, ruim, que Deus não permita desejar isso a alguém". Fonte: "Como evitar uma revolução, mas atender as exigências do povo?". Entrevista à Rádio Finam 19.04.2011 (http://www.yabloko.ru/video/2011/04/19).
}

${ }^{17}$ Cf. Matskevitch, 2017; MUKHIN, 2017, p. 8-11. 
mente negativa) dos processo que ocorreram então na política e na economia e que muitos chamavam de revolução.

Assim, na pesquisa por amostragem do Centro Pan-Russo de Estudos de Opinião Pública feita em 2004 (a pesquisa foi feita dois anos antes do primeiro Maidan ucraniano, protesto que levou à mudança no poder na Ucrânia e influenciou visivelmente a opinião dos cidadãos russos), o conceito de revolução provocava sentimentos positivos em menos de $1 \%$ $(0,69 \%)$ dos entrevistados. ${ }^{18}$ No ano em que a revolução de 1917 completou 90 anos esse número não havia mudado. ${ }^{19}$ Ao mesmo tempo, 30\% em 2004 e $22 \%$ em 2007 tinham sentimentos negativos. ${ }^{20} \mathrm{Em} \mathrm{2005,38 \%} \mathrm{das} \mathrm{pessoas} \mathrm{não} \mathrm{podiam} \mathrm{"justificar}$ de forma alguma" uma revolução como "fenômeno histórico", ocorrido em diferentes países em diferentes momentos, mas um número um pouco maior (42\%) avaliavam-na como uma "inevitabilidade histórica". Apenas 10,5\% viam na revolução uma "chance de renovação". Deve-se observar que o arranjo de posições quase não mudou em 2012, logo depois dos protestos massivos em Moscou. Com uma exceção: a revolução passou a ser vista como uma "chance de renovação" por $15 \% .{ }^{21}$

A influências dos acontecimentos do presente na avaliação dos eventos históricos pode ser vista em relação aos conceitos de "socialismo" e "comunismo", intimamente ligados à revolução na Rússia. É verdade que, no que diz respeito a esses conceitos, os cidadãos russos expressaram uma relação um pouco mais positiva. O socialismo foi positivamente avaliado por cerca de $12 \%$ dos entrevistados em 2004 e 2007; já o comunismo, por $7-8 \%{ }^{22} \mathrm{O}$ socialismo recebeu reações negativas por parte de $11 \%$ dos entrevistas em 2004 e 15\% em 2007; já o

\footnotetext{
${ }^{18}$ Fonte: СРЕОР (ВЦИОМ), março de 2004: https://wciom.ru/zh/print_q.phps_id=14\&q_ id $=1127 \&$ date $=10.03 .2004$

${ }^{19}$ Fonte: СРЕОР (ВЦИОМ), março de 2007: http://wciom.ru/zh/print_q.phps_id=417\&q_ $\mathrm{id}=33490 \&$ date $=18.03 .2007$

${ }^{20}$ Fonte: СРЕОР (ВЦИОМ), março de 2007: https://wciom.ru/index.php?id=236\&uid=4271

${ }^{21}$ Fonte: СРЕОР (ВЦИОМ), 2005 e 2012: https://wciom.ru/index.php?id=236\&uid=113319

${ }^{22}$ Fonte: СРЕОР (ВЦИОМ), março de 2004 e 2007: http://wciom.ru/zh/print_q.php?s_ id=14\&q_id=1128\&date=10.03.2004 e http://wciom.ru/zh/print_q.php?s_id=417\&q_ id $=33491 \&$ date $=18.03 .2007$
} 
comunismo, recebeu $19 \%$ e $26 \%$ de reações negativas nesses mesmos anos. ${ }^{23}$

No período soviético, o culto à revolução foi tornado sagrado. Neste campo de influência se encontravam muitos anticomunistas, que invocavam uma revolução anticomunista. Hoje, na Rússia, são poucas pessoas que compartilham desse culto à revolução. Já na Ucrânia, há uma situação completamente distinta: o mito da revolução nacional - que é alimentado, às vezes inconscientemente, também pela tradição política soviética - exerce uma influência explícita sobre a prática política. ${ }^{24}$

Ao mesmo tempo, negando a revolução como cenário atual e futuro, a população da Rússia contemporânea avalia de maneiras muito distintas a revolução do passado. Os dados das pesquisas nacionais feitas pelo Centro Pan-Russo de Estudos de Opinião Pública, pelo Fundo de Opinião Pública e pelo Centro Levada ("o grande trio" dos centros dedicados ao estudo da opinião pública) mostram a dinâmica da relação para com a Revolução de Outubro desde os anos 1990. Supõe-se que, ao longo dos últimos anos, o conteúdo e os princípios do ensino da história tenham mudado, surgiram novas gerações que estudaram segundo esses novos princípios.

Entretanto, se julgarmos pelo resultado das pesquisas, a relação para com a revolução mudou muitíssimo pouco, se é que mudou. O Centro Pan-Russo de Estudos de Opinião Pública e o Centro Levada perguntaram o quê, segundo a opinião dos entrevistados, a Revolução de Outubro trouxe "aos povos da Rússia". Em 1990, 23\% dos entrevistados concordava com a variante "abriu uma nova era na história dos povos da Rússia". Passados vinte e poucos anos, $25 \%$. Com a opinião de que ela "impulsionou o desenvolvimento social e econômico desses povos" concordaram 26 e $28 \%$ respectivamente. ${ }^{25}$ Contudo, a relação para com a revolução divide a sociedade russa. Em

\footnotetext{
${ }^{23} \mathrm{Idem}$.

${ }^{24}$ Kolonitski, 2014.

${ }^{25}$ Fonte: Centro Levada, outubro de 2011 (em 2017 os percentuais praticamente não mudaram): http://www.levada.ru/2011/11/02/oktyabrskaya-revolyutsiya-prichiny-i-posledstviya/
} 
$1990,18 \%$ das pessoas concordavam que a revolução "freou o desenvolvimento" da Rússia, e praticamente o mesmo percentual $(19 \%)$ vinte anos depois. 12 e $18 \%$ concordavam que "ela foi uma catástrofe para eles [os povos da Rússia]" ${ }^{26} \mathrm{~A}$ pesquisa do Centro Pan-Russo de Estudos de Opinião Pública revelou praticamente os mesmos números, à exceção da variante "foi uma catástrofe para a Rússia". A mudança na formulação da pergunta - de "povos da Rússia" para "país" fez com que a quantidade de pessoas que consideram a revolução uma catástrofe subisse para 18\% em 2012. ${ }^{27}$

Ao longo de quase trinta anos, praticamente não mudou a posição dos grupos populacionais segundo o critério social-demográfico: os mais velhos, com baixa escolaridade, moradores de cidades pequenas e aldeias concordam com a ideia de uma "nova era" mais frequentemente que os demais grupos. Os jovens, com ensino superior, moradores das megalópolis concordam com as avaliações negativas sobre as consequências da revolução com maior frequência do que a média.

Os últimos anos trouxeram pouca coisa nova também na definição das causas da revolução: apenas a variante "difícil situação dos trabalhadores" é nomeada hoje por cerca de metade dos entrevistados, enquanto em 1990 essa resposta era dada por dois terços. Todos os fatores tradicionais restantes, aprendidos ainda na escola, têm aproximadamente a mesma quantidade de adeptos. Como foi dito acima, ainda em 1997, cresceu um pouco a quantidade de defensores da versão sobre a "conspiração dos inimigos do povo russo" como motivo da revolução (de 6 para 11\%). Desde então, o quadro manteve-se estável, até a segunda metade dos anos 2010, quando a versão conspirológica se tornou popular entre $1 / 5$ (20\%) dos entrevistados. Além disso, em 2017, a ideia da "fraqueza do poder governamental" como motivo da revolução se tornou popular entre quase metade ( $45 \%$ ) dos entrevistados. ${ }^{28}$

\footnotetext{
${ }^{26}$ Idem.

${ }^{27}$ Fonte: СРЕОР (ВЦИОМ), outubro de 2012: https://wciom.ru/index.php?i$d=236 \&$ uid $=113319$

${ }^{28}$ Fonte: Centro Levada, março de 2017. 0 total de respostas pode superar os 100\%, já que podia-se escolher mais de uma variante: https://www.levada.ru/2017/04/05/oktyabrskaya-
} 
O que realmente sofreu modificação significativa quando comparado com o período final da perestroika foi a inclinação das pessoas em escolher um ou outro lado do antigo conflito. Ao longo de muitos anos, os pesquisadores propuseram aos entrevistados escolher uma variante de comportamento em 1917. Ao longo desses anos, diminuiu em mais da metade o número daqueles que teriam "contribuído ativamente" ou "contribuído em algo" com os bolcheviques (de $67 \%$ em 1990 para $28 \%$ em 2017). A variante de luta contra os bolcheviques permaneceu igualmente pouco significativa, tanto em 1990 quanto atualmente (de 5 para 8\%). Em compensação, quase dobrou o número daqueles que opinaram que era possível "aguardar" o desfecho dos acontecimentos. Em 1997 e em 2017 essa variante de resposta recebeu o maior apoio, uma vez que foi escolhida por um terço dos entrevistados (33\% contra $18 \%$ em 1990). ${ }^{29}$ A principal tendência dos últimos dez anos (desde 2007) é a negativa em responder e o apelo à variante "difícil dizer". Exatamente assim responde a maioria dos jovens até 30 anos e uma parte considerável daqueles que tem até 45 anos.

De conjunto, segundo dados do Centro Levada, em 2017, 48\% dos cidadãos consideram, com este ou aquele grau de convicção, que a Revolução de Outubro cumpriu um papel positivo na história russa, enquanto $31 \%$ consideram que esse papel foi negativo. ${ }^{30}$ Uma divisão próxima (40\% e $29 \%$ ) foi revelada pelos dados do Fundo de Opinião Pública há 10 anos atrás. ${ }^{31}$

$\mathrm{O}$ número de pessoas que considera Lenin o personagem mais negativo do período da revolução cresceu de 5 para $13 \%$ nesse mesmo intervalo. Ao mesmo tempo, o número daqueles que, entre todos os personagens do período revolucionário, nutrem especial simpatia por Lenin caiu de 67\% em 1990 para $26 \% .{ }^{32}$ Entretanto, em primeiro lugar, Lenin é, de qualquer

\footnotetext{
-revolyutsiya-2/

${ }^{29}$ Fonte: Centro Levada, março de 2017: https://www.levada.ru/2017/04/05/oktyabrskaya-revolyutsiya-2/

${ }^{30}$ Idem.

${ }^{31}$ Fonte: Fundo de Opinião Pública, outubro de 2007: http://bd.fom.ru/report/map/d074421

${ }^{32}$ Fonte: Centro Levada, março de 2017: https://www.levada.ru/2017/04/05/oktyabrskaya-
} 
forma, um dos líderes populares do século 20 (segundo dados de todos os centros de pesquisa). Em segundo lugar, este percentual praticamente não mudou desde 1997. É sintomático o fato de que, como já mencionamos, o presidente Putin tenha se referido negativamente ao papel de Lenin em algumas de suas declarações públicas. Mas ele deve contar com os humores de muitos cidadãos que sustentam outro ponto de vista: ele necessita do apoio dessa parte do espectro político.

Junto com isso, a tentativa de alguns atores de se apresentarem como "herdeiros legítimos" das forças políticas de 1917 leva menos à pacificação do que ao conflito. Um exemplo disso são as iniciativas da deputada da Duma de Estado N. Poklonskaia, que faz lobby por um projeto de memória histórica que coloca no centro da narrativa a figura santificada de Nicolau II, canonizado pela Igreja Ortodoxa Russa. Tal projeto de evidente e agressivo abandono do caráter secular da política da memória oficial contradiz objetivamente a política de "pacificação" declarada, uma vez que as distintas forças sociais, às vezes em oposição umas às outras, não estão preparadas para aceitá-la.

Em especial, surgiu um conflito em torno ao filme do diretor A. Utchitel, cuja estreia oficial está marcada para o fim de outubro (por enquanto, houve apenas exibições não-oficiais)..$^{33} \mathrm{O}$ filme não é antimonarquista. No entanto, a própria tentativa de contar a história do romance pré-nupcial do futuro imperador é recebida por Poklonskaia e outros fundamentalistas ortodoxos como uma ofensa aos sentimentos dos fieis. Isso leva a excessos: ouviram-se chamados para que se incendiasse os cinemas que exibirem o filme, e uma tentativa dessas foi feita. ${ }^{34}$ Enquanto isso, no estúdio cinematográfico em que o filme

-revolyutsiya-2/

33 Trata-se do filme Matilda (Alexei Utchitel, Rússia, 2017), um drama histórico que retrata as relações entre Matilda Kchesinskaia, primeira-bailarina do Teatro Marinski de São Petersburgo, e o herdeiro do trono russo, Nikolau Alexandrovitch, futuro czar Nikolau II. (N. do T.)

${ }^{34}$ Morador de Irbit invadiu o cinema em Ekaterimburgo em que estava sendo exibido 0 filme "Matilda". Suspeito confessou o crime. 04.09.2017: http://www.newsru.com/russia/ 04sep2017/ekat_2.html 
foi rodado, foi jogado um "coquetel Molotov" ${ }^{35}$ Interessante que a polêmica sobre um filme que pouca gente até agora assistiu tenha se tornado a discussão social de maior ressonância no centenário da revolução. Nisso se expressa o conflito relativo ao processo de secularização e dessecularização na sociedade russa contemporânea e, ao mesmo tempo, a surpreendente ausência (segundo a opinião da maioria dos analistas) de outros eventos ligados ao centenário da revolução e que sejam significativos para um amplo círculo de cidadãos russos.

Há muito poucas chances de que os cidadãos mudem sua relação com a revolução ao longo do ano do centenário. Ao contrário, pode-se afirmar que eles preservarão sua "opinião forte". Na Rússia atual, não há praticamente ninguém que não saiba pelo menos alguma coisa sobre os eventos ocorridos em 1917 (embora nossos contemporâneos supervalorizem seus próprios conhecimentos às vezes). Assim, segundo dados do Fundo de Opinião Pública, em 2014, a revolução entrava na lista dos cinco eventos cujas datas a grande maioria (mais de $60 \%$ ) dos cidadãos considerava necessário saber. Além disso, o ano da revolução foi corretamente apontado pela esmagadora maioria $(77 \%)^{36}$, o que supera sensivelmente até mesmo a quantidade daqueles que lembram a data correta de um evento muito mais próximo em termos temporais: o fim da URSS.

Isso não significa que a população russa saiba realmente muito sobre a revolução. Como ocorre com muitos outros eventos históricos, cerca de metade dos russos (47\%) considera seus conhecimentos "ruins" ou "muito ruins". Além disso, esse indicador é maior entre as pessoas com menos de 35 anos (cerca de 60\%). ${ }^{37}$ Por exemplo, em 2007, quando se comemorou amplamente (diferente de hoje) o aniversário de 90 anos da revolução, somente $15 \%$ dos entrevistados afirmou que não

\footnotetext{
${ }^{35}$ Contrários a "Matilda" queimaram automóvel. Portal informativo "Fontanka.ru". 11.09.2017: http://www.fontanka.ru/2017/09/11/011/

${ }^{36}$ Fonte: Fundo de Opinião Pública, setembro de 2014: http://fom.ru/Proshloe/11896

${ }^{37}$ Fonte: СРЕОР (ВЦИОМ), setembro de 2017: https://wciom.ru/index.php?i$d=236 \&$ uid $=116396$
} 
tinha ouvido falar nada sobre a Revolução de Fevereiro. ${ }^{38}$ Entretanto, mais da metade daqueles que "ouviram" ou "sabem" não puderam dizer nada relacionado ao evento. Pelas respostas de cerca de $10 \%$ dos entrevistados, ficou evidente que, em sua memória, se fundiram os eventos de todas as revoluções do início do século 20, não somente a de 1917, mas também a de 1905. Em sua maioria, as repostas foram extremamente vagas: se contentaram em dizer que "viram isso na escola" e fizeram observações genéricas sobre a revolução. Somente $10 \%$ dos entrevistados emitiram julgamentos ou apontaram fatos relacionados especificamente à Revolução de Fevereiro, aos personagens e acontecimentos daquele período específico. $\mathrm{E}$ mesmo assim, foram apontados apenas os fatos mais gerais, encontrados nos livros didáticos soviéticos e nos materiais de propaganda.$^{39} \mathrm{~A}$ situação da memória relativa à Revolução de Outubro é diferente, mas não muito. Cerca de $20 \%$ dos entrevistados fizeram afirmações que tinham uma relação precisa com os eventos de outubro de $1917 .{ }^{40}$ Mas as afirmações feitas também não extrapolavam os limites dos livros didáticos soviéticos sobre história. Dentre as considerações feitas, predominavam as negativas, que descreviam o caos e a destruição, mas sem quaisquer detalhes. É evidente que, neste caso, estamos lidando com o lado emocional da memória sobre a revolução, uma memória fundada não sobre conhecimentos históricos, e sim dependente sobretudo dos fatos, sentimentos e valores do tempo presente.

Em parte, a explicação para essa situação pode estar no fato de que um nível comparativamente maior de conhecimento histórico (independentemente da distância temporal entre o fato histórico e o presente) foi encontrado somente entre os nascidos antes de 1975, ou seja, entre aqueles que concluíram o ensino escolar ainda no período soviético). Dessa forma, as pesquisas massivas, regra geral, revelam associações (principalmente aquelas ligadas às figuras históricas) próprias dos

\footnotetext{
${ }^{38}$ Fonte: Fundo de Opinião Pública, fevereiro de 2007: http://bd.fom.ru/report/map/d070825 ${ }^{39}$ Idem.

${ }^{40}$ Fonte: Fundo de Opinião Pública, outubro de 2007: http://bd.fom.ru/report/map/d074421
} 
grupos de maior idade, associações essas absorvidas por esses grupos ainda no período soviético. As gerações mais jovens, como regra, não respondem às "perguntas abertas" (que propõem ao próprio entrevistado formular a resposta) ligadas à história, reconhecendo a ausência de conhecimentos sobre tal tema.

Em recente pesquisa por amostragem do Centro Pan-Russo de Estudos de Opinião Pública (2017), 27\% dos entrevistados indicaram corretamente o nome do último chefe do Governo Provisório, A. Kerenski. ${ }^{41}$ Ao mesmo tempo, nessa pergunta, assim como em todas as outras ligadas à história, evidencia-se uma grande diferença entre as gerações. Entre as pessoas com menos de 35 anos, 5-6\% responderam corretamente; entre 35 e 40 anos - 19\%; e entre aqueles com mais de 45 anos $42-43 \%{ }^{42}$ Ao longo dos últimos anos, esse afastamento entre as gerações de russos em termos de conhecimento histórico só aumentou. Inclusive, o conhecimento daqueles que concluíram o ensino escolar há pouco tempo é significativamente pior do que o daqueles que concluíram o ensino médio há três ou quatro décadas. Isso pode ser explicado pelo processo, observado em muitos países, de mudança daquilo que se considera "necessário" saber e a percepção da necessidade de adaptação a uma certa "norma". Entretanto, segundo dados de pesquisas nacionais, nos países da Europa e América, não se observa tanta discrepância entre as gerações mais velhas e as mais jovens.

Uma discrepância tão grande quanto esta no conhecimento dos russos é vista também na questão "quem os bolcheviques derrubaram"? Somente $11 \%$ respondem corretamente: "o governo Kerenski". Além disso, as respostas corretas variam de $1-3 \%$ entre os grupos mais jovens até $14-19 \%$ entre os mais velhos. ${ }^{43}$ Ao que tudo indica, a maioria dos cidadãos russos considera que foi exatamente a Revolução de Outubro que le-

\footnotetext{
${ }^{41}$ Fonte: СРЕОР (ВЦИОМ), setembro de 2017: https://wciom.ru/index.php?i$d=236 \&$ uid $=116396$

42 Idem.

${ }^{43}$ Idem
} 
vou ao fim da monarquia, e não a Revolução de Fevereiro. Isso está em consonância com o fato de que quase metade dos entrevistados concordou com a variante de resposta proposta: "A Revolução de Fevereiro de 1917 não teve, por si só, nenhum significado, sendo simplesmente uma primeira etapa (preparatória) da Revolução de Outubro". ${ }^{44}$

Vale observar mais um aspecto: pela forma como os pesquisadores formularam as perguntas e as variantes de respostas, fica bastante visível que os autores das perguntas compartilham de muitas das visões difundidas hoje sobre o passado, inclusive sobre a revolução de 1917, sendo que nem todas essas visões são confirmadas pela pesquisa histórica contemporânea.

Entretanto, uma "opinião forte", junto com um nível não muito elevado de conhecimento histórico, é um fator muito importante que influencia na percepção das mensagens informativas. Por isso, percepções tão diferentes, frequentemente opostas, sobre a história da Revolução Russa permanecerão. Pode ser que haja uma demanda por pacificação na Rússia, mas não se observa o desejo de encontrar uma visão consensual sobre os fatos de cem anos atrás, nem a tentativa de corrigir suas próprias visões.

Nessa situação, as ações do presidente Putin e seu círculo próximo são, a seu modo, pragmáticas, pois levam em consideração as particularidades da opinião pública na Rússia contemporânea. A tarefa de "pacificação", declarada OFICIALMENTE, não é realizável no próximo período. Por isso, a memória sobre a revolução é considerada inadequada para uso político. As esferas do poder permitem uma discussão histórica relativamente livre em círculos científicos, às vezes até mesmo oferecendo ajuda financeira às distintas iniciativas. Entretanto, os debates entre os pesquisadores não têm grande significado social e estão propositalmente limitados às fronteiras das "reservas" acadêmicas. Outras forças políticas - à exceção, talvez, da Igreja Ortodoxa - também não consideram

${ }^{44}$ Fonte: Centro Levada, janeiro de 2017: http://www.levada.ru/2017/02/14/fevralskaya-revolyutsiya-1917/ 
a memória sobre a revolução útil para a utilização política nos dias de hoje.

É difícil construir hipóteses sobre os eventos comemorativos oficiais e não-oficiais marcados para outubro e novembro de 2017, pois a situação socio-política é bastante indefinida. Pode-se apenas supor que as instituições do poder vão continuar a não utilizar o recurso do centenário, evitando assim que o status quo sofra qualquer abalo. A ausência de quaisquer ações por parte do Estado em fevereiro-março (centenário da queda da monarquia) fala em defesa deste prognóstico. E não parece que a sociedade exerça aqui qualquer influência.

\section{Referências Bibliográficas}

BASTIÉ, Eugénie. "Centenaire de 1917: "Poutine préfère Staline à Lénine" (un entretien à Michel Eltchaninoff). Le Figaro, 24/03/2017. Disponível em: http://www.lefigaro.fr/vox/histoire/2017/03/24/31005-20170324ARTFIG00338-centenaire-de-1917-poutine-prefere-staline-a-lenine.php

КАЛИНИН И. Призрак юбилея. Неприкосновенный запас, № 111 (1/2017). (http://nlobooks.ru/node/8279)

KOLONITSKI, Boris. "Resursi kulturnoi pamiati i politika pamiati o pervoi mirovoi voine v Rossii" // Cahiers du Monde Russe. 2017. N $^{\circ} 58$ (1-2). pp. $179-202$.

"Why Russians Back Putin on Ukraine". The New York times. 11 de março de 2014. Disponível em: https://www.nytimes.com/2014/03/12/opinion/why-russians-back-putin-on-ukraine.html

MAC FARQUHAR, N. 'Revolution? What Revolution?' Russia Asks 100 Years Later". The New York Times, March 10, 2017. Disponível em: https://www.nytimes.com/2017/03/10/world/ europe/russian-revolution-100-years-putin.html

MATSKEVITCH, M. "O que revelou de inesperado a pesquisa de qualidade feita entre os jovens que foram à manifestação do dia 11 de abril de 2017" (http://www.online812.ru/2017/04/11/011/) 
MUKHIN, A. "Pesquisa de qualidade entre manifestantes". Go$\operatorname{rod} 812,2017$, № 7 (362).

POMERANZ, William E. "Why Putin will be skipping the 100th anniversary of the Russian Revolution". Wilson Center Kennan Institute Blogs, February 22, 2017. Disponível em: https:// www.wilsoncenter.org/blog-post/why-putin-will-be-skippin$\mathrm{g}$-the-100th-anniversary-the-russian-revolution

ПОНОМАРЕВА, Е. Помнить уроки прошлого: Известия, 20.02.2017 (https://iz.ru/news/664618)

SCHMEMANN, S. "The Russian Revolution: Then and Now". The New York Times, March 16, 2017. Disponível em: https:// www.nytimes.com/2017/03/16/opinion/the-russian-revolution-then-and-now.html

ШЕЛИН С. "Власть больше не управляет ни будущим, ни прошлым". Информационное агентство Росбалт, 31.03.2017 (http://www.rosbalt.ru/blogs/2017/03/31/1603794. html)

ЯКОВЛЕВА Е. “Февраль и олигархи: Мединский напомнил о главных причинах и уроках февральской революции”, Российская газета, 18.02.2017 (https://rg.ru/2017/02/18/medinskij-napomnil-o-glavnyh-prichinah-i-urokah-fevralskoj-revoliucii.html)

Portal oficial do Presidente da Rússia: http://www.kremlin.ru/

Centro Levada: https://www.levada.ru/

СРЕОР (ВЦИОМ): https://wciom.ru/

Portal informativo "Fontanka.ru": http://www.fontanka.ru/

Fundo de Opinião Pública: http://bd.fom.ru/

Tradução: Henrique Canary ${ }^{45}$ 